Bol. Acad. peru. leng. 63. 2018 (97-127)

\title{
APROXIMACIÓN AL TRATAMIENTO LEXICOGRÁFICO DE VERBOS CAUSATIVOS DE PERCEPCIÓN EN EL DICCIONARIO DEL ESPAÑOL ACTUAL
}

\section{APPROACH TO THE LEXICOGRAPHIC TREATMENT OF CAUSATIVE VERBS OF PERCEPTION IN THE DICCIONARIO DEL ESPAÑOL ACTUAL}

\author{
Gretel Gutiérrez Fuentes \\ Universidad de La Habana
}

\section{Resumen:}

Si bien son los diccionarios de valencias y los de construcción y régimen los que mejor recrean la información sintáctica, se reconoce la utilidad de que el diccionario no se limite a brindar herramientas para la decodificación, sino que contribuya a la codificación de la lengua. Para tal propósito, interesan, para este trabajo, las noticias sobre la posible combinatoria de los elementos que pueda darse, entre ellas - y aplicado en especial a los verbos-, las relativas a la transitividad e intransitividad, el contorno lexicográfico y el tipo de definición frecuente. Se estudia el tratamiento lexicográfico que reciben algunos verbos causativos de percepción en el Diccionario del español actual (DEA). El análisis de los artículos lexicográficos de este tipo de verbos reveló que es posible encontrar usos transitivos e intransitivos, ejemplos de alternancia causativa, y contornos lexicográficos que suelen ser integrados y heterogéneos 
https://doi.org/10.46744/bapl.201801.004

sobre todo en las factitivas con el verbo hacer, que resultaron las más frecuentes. Se verificó que ver se usa en la mayoría de las acepciones, referidas a la percepción visual, como núcleo semántico en los sintagmas definicionales.

\section{Abstract:}

Although dictionaries of valences and those of regime and construction are the best to recreate syntactic information, we recognize that dictionaries are useful not only to provide tools for decoding, but also to contribute to language codification. For this purpose, news about the possible combination of elements are of interest for this work, - and especially applied to verbs-, those related to transitivity and intransitivity, the lexicographic contour and the type of frequent definition. We study the lexicographic treatment of some causative verbs of perception in the Diccionario del español actual (DEA). The analysis of the lexicographic articles of this type of verbs revealed that it is possible to find transitive and intransitive uses, examples of causative alternation, besides, that the lexicographic contour tends to be integrated and heterogeneous especially in the factitive ones with the verb hacer, which were the most frequent. It was verified that ver is used in most of the definitions, referred to the visual perception, as semantic head in the definitional phrases.

Palabras clave: verbos causativos; percepción; transitividad; definición factitiva; contorno lexicográfico.

Key words: causative verbs; perception; transitivity; factitive definition; lexicographic contour.

Fecha de recepción: $\quad 30 / 03 / 2018$

Fecha de aceptación: 31/05/2018 
https://doi.org/10.46744/bapl.201801.004

\section{Introducción}

Si bien los diccionarios de valencias y los de construcción y régimen son los que mejor recrean la información sintáctica, se reconoce la utilidad de que el diccionario no se limite a brindar herramientas para la decodificación, sino que contribuya, asimismo, a la codificación de la lengua.

Para tal razón interesan las noticias sobre la posible combinatoria de los elementos que pueda ocurrir, entre ellas - y aplicado en especial a los verbos-, las relativas a la transitividad e intransitividad presentes al inicio de los artículos lexicográficos. En tal sentido, «[...] cuando el diccionario nos informa de que un determinado verbo es transitivo, nos está diciendo cómo se construye, es decir, nos aporta cierta información contextual relativa a sus complementos posibles $\mathrm{o}$ necesarios» (Bosque, p. 51).

De igual forma, el contorno lexicográfico, en palabras de Bosque, «el poderoso instrumento restrictivo» del que dispone la lexicografía, indicará no solo las posibilidades sintagmáticas, sino que también contribuirá a configurar el significado del verbo en cuestión.

Ahora bien, se ha elegido el Diccionario del español actual (DEA), dado que la información gramatical en este ocupa un lugar importante, en tanto se atiende a que «el contenido de una voz está articulado en dos vertientes, que son su valor semántico y su valor sintáctico, y [...] la definición, por tanto, debe describir ambas vertientes» (Seco, Andrés, \& Ramos, 2005:13).

Finalmente, el presente trabajo muestra - en un primer acercamiento que no pretende ser exhaustivo - el tratamiento lexicográfico que reciben algunos verbos causativos de percepción en el $D E A$. En específico, se intenta hacer generalizaciones a partir de la descripción de determinados aspectos, tales como la posibilidad de admitir usos intransitivos junto a los transitivos (que son los descritos como más frecuentes para la clase de verbos elegida), la contribución del contorno para explicitar los argumentos del definido, así como el tipo de definición frecuente. 
https://doi.org/10.46744/bapl.201801.004

\section{Referentes teóricos}

\subsection{Transitividad e intransitividad}

Bajo las marcas de «(v) tr. o intr.» suelen presentarse, en los diccionarios de lengua, los verbos que aparecen en la obra. Según un vaciado exploratorio de las primeras 380 páginas de la letra $A$, en el $D E A$, los artículos lexicográficos correspondientes a verbos marcados únicamente como transitivos son los más numerosos (471), a continuación, aquellos que admiten ambas posibilidades (entre los que sobresalen los que presentan un primer subgrupo transitivo y, luego, un segundo intransitivo (136); frente a los que, por el contrario, primero agrupan los intransitivos y luego las transitivos (31) y, finalmente, los que solo se marcan como intransitivos (103). Esta distribución entre transitividad e intransitividad cobra especial interés, en tanto se sustenta en ejemplos de uso real de la lengua que recoge el $D E A$.

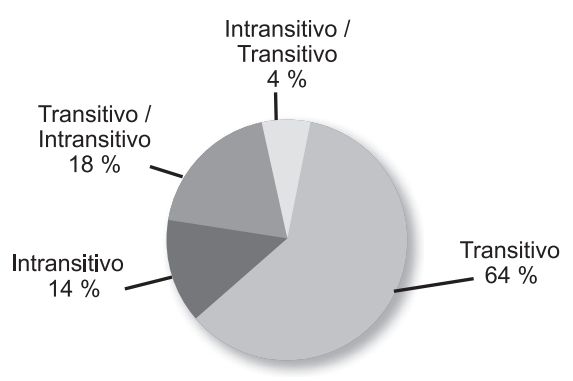

Figura I. Distribución de verbos transitivos e intransitivos

La distinción entre verbos transitivos e intransitivos es de larga data. Los primeros suelen ir acompañados de un complemento u objeto directo que, según la RAE-ASALE (2009: 2592), se corresponde con «aquella función sintáctica que depende del verbo y que puede ser desempeñada, dentro del grupo verbal por varios segmentos sintácticos», de carácter nominal; mientras que no es así en los segundos.

En este sentido, se ha dicho que un verbo no es considerado aisladamente ni transitivo ni intransitivo, sino que es la función en la 
https://doi.org/10.46744/bapl.201801.004

frase la que le aporta dicho carácter. Algo semejante a lo que sucede con la sustantivación o adjetivación podría determinarse para el verbo el carácter transitivo, frente a la función transitiva en un caso dado (Roca Pons, 1968). Así, «verbos como hacer, decir, llevar son verbos transitivos que siempre necesitan complemento directo», mientras que otros como comer y beber podrán aparecer en la frase con o sin dicho complemento.

Por otro lado, se da en algunos verbos que el cambio de transitivo a intransitivo no repercute de forma verdadera en la significación. Así, los verbos pasear o pasar, básicamente intransitivos, pueden emplearse como transitivos cuando adquieren un sentido factitivo: $L a$ mamá pasea a su bebé; Juanita pasa las páginas del libro con mucho cuidado (Roca Pons, 1968).

Asimismo, suele hablarse de la significación incompleta de los transitivos frente a los intransitivos. Roca Pons dice que esto es solo verdad en parte, pues hay verbos intransitivos que necesitan de igual forma a sus complementos como es «el caso de ir, que necesita el complemento circunstancial de lugar y que no puede estar solo» (Roca Pons, 1968).

Por otra parte, se concibe el complemento directo como especificador de la idea verbal por ejemplo: colgar a una persona 'ahorcar', colgar una foto en internet 'publicar', le colgaron el robo 'imputar' o 'achacar'. Nótese que en estos casos, aunque entre todos hay un sema común o de infraespecificación (quizás el de 'suspender (en lo alto)'), pudiera decirse que adquiere el verbo colgar matices diferentes, que también dan lugar a sinónimos diferentes para cada uno de ellos. Al respecto, se lee que «en una determinada estructura oracional, el verbo se siente incompleto, necesitado de precisión significativa; por ello, verbo y complemento suelen formar una unidad, en cierto modo autónoma, en cuanto a significación (Cano, 1987: 26). Asimismo, se señala que no necesariamente el carácter más o menos preciso de un verbo tendrá que depender de la exigencia de un complemento directo. Si bien para Alarcos es una gradación léxica no gramatical: verbos de signo léxico muy amplio necesitados de preci- 
sión» (como hacer o tener), frente a verbos de sentido concreto, que no la necesitan» ${ }^{1}$.

Frente a que la transitividad o la intransitividad en un verbo son fruto de los usos o las interpretaciones que los hablantes hayan podido darle a tales vocablos a lo largo de la lengua, Alarcos (1970: 13) y Morera (1989: 44) ${ }^{2}$ defienden que no es en el uso donde tal posibilidad puede explicarse, sino que tal clasificación es algo intrínseco a su significado (Mendikoetxea, 1999: 1578).

De igual forma, según la RAE-ASALE (2009), hay verbos intransitivos $^{3}$ por naturaleza que pueden construirse con complementos de acusativo interno: Vivir una existencia miserable..., en estos complementos se advierte la cercanía o «afinidad» con el verbo. Tal cercanía alcanza a los «llamados complementos cognados», que reflejan la base léxica del verbo o que «se asocian a este mediante otro proceso morfológico». La presencia de tales complementos se justifica y avala solo si van acompañados de un «modificador restrictivo que aporte información nueva».

Se formula entonces que para definir ambos tipos de verbos deberá atenderse más bien a los criterios semánticos y sintácticos, de modo que los transitivos denoten un estado o evento que requiere la existencia de dos participantes o argumentos, mientras que los intransitivos requerirán un solo argumento o participante que se realice sintácticamente como sujeto de la predicación. Además, se añade que tal división no se alterará: aunque aparezcan objetos «no se les verá como participantes en la acción verbal porque son internos a esta, de ahí que se mantenga la clasificación del verbo como intransitivo». El único argumento de un verbo intransitivo será bien agente o tema o paciente (no puede considerarse como instigador del evento que denota el verbo, sino como el elemento que sufre o padece la acción) (Mendikoetxea, 1999: 1578-1579).

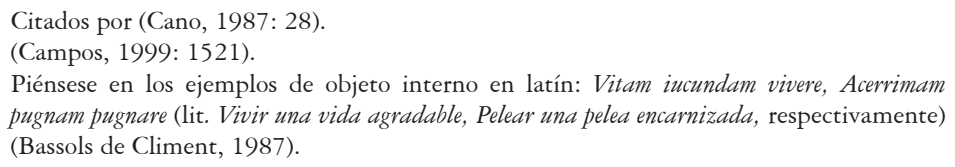
pugnam pugnare (lit. Vivir una vida agradable, Pelear una pelea encarnizada, respectivamente) (Bassols de Climent, 1987). 
https://doi.org/10.46744/bapl.201801.004

\subsubsection{Verbos causativos. Alternancia causativa}

Entre los verbos que presentan alternancias entre usos transitivos e intransitivos se hallan los causativos. El adjetivo causativo (-a) es definido, para Casares, como: «Que es origen o causa de alguna cosa» ${ }^{4}$. Y, en efecto, las acciones que denotan estos verbos, según la RAE-ASALE (2009: 666), implican o propician efectos que «pueden expresarse por adjetivos (limpiar 'hacer que quede limpio'), por verbos (matar 'hacer morir') o por ambos (romper 'hacer que se rompa o que quede roto')».

Asimismo, se informa que es posible constatar para otros verbos, que también alternan usos transitivos e intransitivos, una interpretación causativa que es posible parafrasear por «hacer + infinitivo». Tal es el caso de subir (en Subieron los precios), y en la acepción transitiva los precios representaría el complemento directo (en tanto habría un sujeto (ellos) que realizaría tal acción (bicieron subir los precios). Algo semejante se reporta para los verbos referidos a cambios de estado (hervir, ingresar, parar, engordar...) (RAE-ASALE, 2009).

Frente a lo anterior descrito, es frecuente que en la interpretación no causativa intervengan correlatos intransitivos pronominales «que por lo general denotan algún cambio físico o psíquico». Tal es el caso de lo que sucede con los verbos causativos de percepción, objeto de estudio de nuestro trabajo.

Los verbos causativos suelen participar en lo que se denomina «alternancia causativa», lo que explica el comportamiento de verbos que, como romper, antes mencionado, tienen una variante transitiva (con sujetos como Juan, el hacha, el huracán...) y una inacusativa, en la que el sujeto sintáctico es objeto nocional. Para este último tipo de construcción, en cuanto a sus características morfosintácticas, puede mencionarse que se caracteriza por presentar el pronombre clítico se (razón por la cual, según Mendikoetxea (1999: 1589), suele ser etiquetada como pronominal).

4 Citado por (Lema, 1981: 14).

Bol. Acad. peru. leng. 63(63), 2018 / e-ISSN: 2708-2644 
Los verbos que participan en la alternancia causativa sufren un proceso de «detransitivización» o «decausativización» por el cual, en la construcción inacusativa, no aparece expresado el sujeto nocional que se corresponde con la causa externa de la consecución del evento que denota el verbo. Cuestión que deberá tenerse en cuenta para la distribución de acepciones en un diccionario(s) monolingüe(s), referidas a tales verbos, como se verá más adelante, por las variaciones en la estructura argumental a que da lugar (Mendikoetxea, 1999: 1590).

Por tanto, si el número de actantes es aumentado, se puede decir que el nuevo verbo, susceptible de llevarlos, es causativo respecto del antiguo: derribar es el causativo de caer, así como mostrar es el de ver.

\subsection{Estructura argumental: predicado y argumento}

\subsubsection{Concepto de predicado}

Se reconocen para la noción de predicado al menos dos sentidos. De estos, el primero se identifica con el grupo verbal cuyo contenido alude al referente del sujeto: en una oración como María come manzanas, el elemento subrayado sería el predicado, mientras que María sería el sujeto. El segundo de los sentidos es el que se asumirá en este trabajo. Se entiende el predicado entonces como categoría que designa estados, acciones, propiedades o procesos en los que intervienen uno o varios participantes. La relación que establece el predicado con dichos participantes es muy estrecha, pues están previstos en el significado. Esto es razón para que, ante un nuevo verbo, por ejemplo, interese conocer los rasgos que lo definen, así como sus posibilidades de combinación. De ahí que, en un ejemplo como el primero, el predicado de la oración es comer y relaciona dos argumentos o actantes (María, manzanas).

\subsubsection{Concepto de argumento}

Argumento o actante será aquel elemento que es seleccionado o elegido por cada predicado en función de su significación. De ahí que mantenga con este último una relación muy cercana y que en él se realicen las funciones sintácticas — «que representan las formas mediante las que se manifiestan las relaciones que expresan los argumentos»— «de 
primer nivel»: sujeto, complemento directo, indirecto 5 y suplemento. $\mathrm{Al}$ conjunto ordenado o no de tales argumentos, se llamará estructura argumental. De ahí que «los argumentos de un predicado representan, en cierta forma, un esqueleto de su significación que se obtiene por abstracción o por reducción de las informaciones que el diccionario proporciona cuando los define» (RAE-ASALE, 2009: 64).

\subsubsection{Tipos de argumento}

Como ya se adelantaba en el acápite anterior, entre los argumentos que requiere un predicado (por excelencia verbal, que será el tipo de predicado a tratar en este trabajo), se marcarán los relativos al sujeto, complemento u objeto directo, complemento indirecto ( $v i d$. Nota 5), así como el suplemento o complemento de régimen. Luego, según el sentido de predicado asumido, La maestra daba los libros a los niños nuevos, el sujeto (La maestra) se opondría a los libros y a los niños nuevos, en tanto argumentos todos del predicado dar. Así visto, se advierte que los argumentos de un predicado, entonces, estarán pedidos o exigidos por su «naturaleza semántica», mientras que la forma en que se actualicen estará determinada por la sintaxis: «La estructura argumental de los predicados debe ser completada con la que aportan las funciones sintácticas, puesto que no es —en sí misma- información de naturaleza formal que sea visible de manera directa en la sintaxis, y también porque esa información combinatoria puede ser variable» (RAE-ASALE, 2009: 67).

Por otra parte, si se atiende al número de argumentos pedidos o exigidos por un predicado, podrá clasificarse este último en cuanto a su valencia («y también aridad o adicidad del verbo (Bosque \& GutiérrezRexach, 2007: 254)»). Se explica, asimismo, que las clasificaciones atribuidas a los verbos, en cuanto a sus posibilidades combinatorias (transitivos, intransitivos, impersonales...), pudieran ser «una consecuencia de la valencia de los verbos», y que a partir de esta podrían agruparse en avalentes, monovalentes, bivalentes y trivalentes (para los primeros podrían indicarse verbos como los meteorológicos: Llueve mucho aquí;

5 El complemento indirecto podrá o no representar un argumento, por ejemplo, con el verbo dar en Le dio su bolsillo, donde es exigido por el verbo, pero no en Voy a lavarle la ropa a Lucía, donde, según (RAE-ASALE, 2009), no es exigido en función de su significado. 
para los segundos, La niña sonríe; para los terceros, La niña quiere agua $\mathrm{y}$, para los últimos, La niña envía correos a su papá). «Un verbo monovalente, monádico, o de un lugar (los cuatro términos se usan) será aquel que tome un solo argumento; un verbo bivalente, binario, diádico o de dos lugares será aquel que tome dos argumentos; y un verbo trivalente, ternario, triádico o de tres lugares será aquel que tome tres argumentos» (Bosque \& Gutiérrez-Rexach, 2007: 254).

En este sentido, se añade que no se da una total equivalencia entre las clasificaciones de monarios o monovalentes y los intransitivos, o binarios, y los transitivos «fundamentalmente porque estos términos designan propiedades de los verbos asociadas a determinadas funciones sintácticas. Es transitivo el verbo que tiene un complemento directo (un $\mathrm{SD}$ que recibe caso acusativo), y ditransitivo el que tiene complemento directo y uno indirecto. Estas propiedades están vinculadas con la valencia, pero no son equivalentes a ella» (Bosque \& Gutiérrez-Rexach, 2007: 254). Para tal, se propone el ejemplo de los verbos comprar y carecer que, aunque ambos demandan dos argumentos: Juana compró el mantell La empresa carece de recursos, se clasifican en $D E A$, por ejemplo, como transitivo e intransitivo, respectivamente ${ }^{6}$.

Por otro lado, aun cuando se determina la valencia de cada uno de los predicados, o lo que es lo mismo, el número de argumentos que requieren para estar completos o saturados ${ }^{7}$, existe la posibilidad de que un grupo de argumentos pueda omitirse en una determinada realización sintáctica del predicado. De ahí que se produzca, al menos superficialmente, un cambio en la estructura argumental (aunque en muchos casos el omitirse un argumento no implique que un verbo $x$ pierda su carácter transitivo). De hecho, no todos los argumentos de un predicado constituyen segmentos obligatorios, sino que habrá algunos argumentos que quedan o puedan quedar implícitos o sobrentendidos, por ejemplo: Casi

6 Comprar (2005: 1150) y carecer (2005: 885).

7 Para que una expresión denote una proposición completa, el elemento subcategorizador (el verbo en el caso de la oración) tiene que haberse combinado con todos los constituyentes que subcategoriza. Suele denominarse a esta condición requisito de saturación argumental completa. Una expresión estará completamente saturada cuando se hayan satisfecho sus requisitos de subcategorización o selección categorial (Bosque \& Gutiérrez, 2007: 254). 
nunca me escribes / Casi nunca me escribes cartas. Por tanto, el que se describa la estructura argumental del predicado no implicará que los argumentos forzadamente se presenten todos y en todo momento, sino que podrá darse el caso de que alguno pueda no realizarse sintácticamente; pero esto dependerá del contexto y del propio predicado, y no cualquier argumento podrá estar en esta situación.

Otra consecuencia de la variabilidad de la estructura argumental, según Escandell (2011), es la que ocurre cuando un mismo verbo se puede construir en estructuras diferentes (como es el caso de los verbos de alternancia causativa (v. acápite 1.2 ): La leche hierve / Juana bierve la leche), lo que conlleva al cambio de acepción en un diccionario como por el ejemplo el $D E A$, en el que se subdivide el artículo lexicográfico en dos subgrupos (como muestra de las dos «alternativas construccionales» para este verbo): uno primero que agrupa las acepciones intransitivas y, por consiguiente, monovalentes, es decir, en las que solo se resalta la presencia del argumento requerido por este tipo de predicado, el sujeto: [un líquido]. Mientras que en el segundo subgrupo se reúnen las transitivas para las que se señala el argumento referido al complemento directo [un líquido $(c d)$ ], y con la marca de (tr.) también la participación de un argumento sujeto.

\subsubsection{El enfoque de la semántica composicional}

A continuación, se añaden algunas anotaciones sobre la noción de predicado primero, y sobre la de argumento, después, desde el enfoque de la semántica composicional.

La noción de predicado no es privativa de los verbos (aunque sea a estos a los que se dedique el trabajo), sino que puede extenderse también a sustantivos y adjetivos y, con ello, la posibilidad de admitir complementos.

De ahí que los sustantivos, adjetivos y verbos se encuentran dentro de las unidades léxicas que si bien son categorías diferentes en cuanto a sus propiedades morfológicas, sintácticas y combinatorias, es posible agruparlas a partir del aporte semántico que proporcionan al significado 
de una expresión compleja. Es decir, estas unidades simples participan en la conformación componencial de dicho significado.

Luego, desde el punto de vista semántico, los nombres comunes, los adjetivos calificativos y los verbos comparten la capacidad de denotar conjuntos de entidades, de forma tal que imponen a un determinado elemento, los rasgos comunes, suficientes y necesarios para que pertenezca a un conjunto $x$. El elemento aceptado estará comprendido dentro de la definición extensional, es decir, formará parte del conjunto de entidades que el nombre común, el adjetivo calificativo o el verbo denoten y, además, su definición intensional se corresponderá con el conjunto de rasgos semánticos que se asocien sistemáticamente a dicho conjunto $x$. «El verbo cantar se asocia entonces con su extensión o conjunto de aplicación en una situación concreta. Por el contrario, la intensión de cantar será el concepto o la propiedad expresados» (Bosque \& Gutiérrez, 2007: 252).

Luego, la noción de predicación que se sigue es semántica, en tanto se concibe como una "condición relativa al significado de las expresiones». Asimismo, «los análisis logicistas pusieron de manifiesto que la estructura predicativa de las oraciones es una parte sustancial de su significado» (Bosque \& Gutiérrez-Rexach, 2007: 251).

En relación con los argumentos, ya se veía de alguna forma que estos pueden definirse como cada una de las expresiones requeridas por el predicado para poder cerrarse, completarse, saturarse... De ello puede inferirse que cuando los argumentos están sin especificar, esto es, tal cual se presentan en las definiciones de los diccionarios, su lugar lo ocupan variables. Piénsese, por ejemplo, en la definición del predicado dar, cuyos argumentos (alguien, algo, a alguien) se presentan como $x, y, z$, y quedan como fórmulas abiertas que no podrán ser verdaderas o falsas hasta no actualizarse en una proposición y asumir entonces un valor concreto.

\subsection{La definición lexicográfica de los verbos}

Aun cuando se ha extendido, en páginas anteriores, la noción de predicado a sustantivos y adjetivos, y con esto la posibilidad de admitir argumentos, será el verbo, como «auténtico núcleo oracional», la categoría 
https://doi.org/10.46744/bapl.201801.004

gramatical en la que - a diferencia de estas dos categorías nominalesdisminuya el grado de opcionalidad de los argumentos según Escandell (2011). La definición lexicográfica de la clase verbal demandará, por consiguiente, requisitos adicionales.

Si se sigue un concepto amplio de definición, según el cual esta se identifica con «todo tipo de equivalencia establecida entre la entrada y cualquier expresión explicativa de la misma en un diccionario monolingüe» (Porto Dapena, 2002: 269), podrá aceptarse que, referido a los verbos, una definición deberá comprender, en principio, dos partes fundamentales, una referida al enunciado parafrástico y otra, al contorno definicional. La primera incluye los «rasgos semánticos intrínsecos del definiendum»y, por tanto, los que le permiten ubicarse dentro de un «paradigma léxico-semántico», mientras que la segunda, los «rasgos contextuales o de subcategorización» que dan cuenta de las posibilidades combinatorias (o se detienen en lo "puramente sintagmático») del verbo en cuestión y que contribuyen - ya se adelantaba- a que el diccionario auxilie no solo en la decodificación de la lengua, sino también en la codificación.

Aunque no es objetivo de este trabajo abarcar todas las posibilidades definicionales con los verbos, interesa ofrecer unos referentes mínimos que apoyen la explicación e interpretación a desarrollar en el próximo capítulo dedicado al análisis de los verbos.

En este sentido, según Porto Dapena (2002), el tipo de definición más frecuente para los verbos es la incluyente positiva, mediante la que el verbo se define por medio de otro verbo de significado más general, un archilexema, al que modifican uno o varios complementos, con los que es posible marcar «la diferencia específica». Esta podrá estar constituida "por cualquier tipo de complemento verbal: un adverbio o expresión equivalente, un objeto directo, un predicativo, etc.»; mientras que el archilexema deberá atender a la clase de verbos a que pertenezca el definido. Así, para un definiendum intransitivo, el archilexema podrá representarse por cualquier tipo de verbo (transitivo, pronominal o intransitivo), pero, si es transitivo, habrá de ser también transitivo. 
Ahora bien, un tipo de definición que estará presente en varios de los verbos que se analizan en este trabajo será la definición factitiva que Porto Dapena ubica entre las clasemáticas (2014: 179).

Un verbo será factitivo respecto de otro "cuando presenta el proceso indicado por este como consecuencia de una acción realizada sobre su propio sujeto»; es decir, será un sujeto que no realiza la acción por sí mismo, sino que la hace realizar a otro u otros. «Desde lo sintáctico, el sujeto del verbo no factitivo pasa a ser objeto directo o indirecto con el factitivo, porque la factitividad es una relación intersubjetiva; por eso, según muy bien observa B. García Hernández (1980: 79, nota 15) se trata más que de un clasema aspectual, de una diátesis» (Porto Dapena, 2014: 179).

Por otra parte, se establecen grados para la factitividad: de primer grado, cuando el verbo no factitivo es intransitivo y, por lo tanto, su sujeto es objeto directo del factitivo (matar. tr. Hacer morir [a un animal o persona] / enseñar. tr. Hacer que [otro] aprenda [algo].); frente a una de segundo grado, porque ambos verbos, factitivo y no factitivo son transitivos y, por tanto, tienen el mismo objeto directo y es el objeto indirecto del factitivo el que desempeña la función de sujeto en el no factitivo (Porto Dapena, 2014: 179).

Ahora bien, desde el punto de vista formal, este tipo de definición es siempre de carácter complejo, está constituida por dos verbos: hacer (que funciona como núcleo sintáctico y al que, por tanto, se subordina el primero) y el verbo no factitivo con respecto al definido. Desde el punto de vista semántico, el verbo hacer aporta los contenidos categorial y clasemático: su misión es convertir al otro en factitivo —y de paso también en transitivo, cuando no lo es-, mientras que el contenido léxico viene dado por el verbo subordinado, que, por ello, desempeña la función de núcleo semántico (Porto Dapena, 2014).

Debe aclararse, como lo hace el profesor Porto Dapena (2014: $184)$, que puede darse que un verbo factitivo no se defina «necesaria- 
mente» de forma factitiva, sino que es posible que se asuma otra variante, como por ejemplo la de: matar. intr. Quitar la vida ${ }^{8}$.

Además, un verbo puede ser «neutro» desde el punto de vista de la factitividad, pues podrán constatarse para dicho verbo usos tanto factitivos como no factitivos. Esto tendrá como consecuencia la aparición «de lo que para algunos serían acepciones diferentes, aunque en realidad se trate más bien de meras subacepciones o variantes de una misma acepción» (Porto Dapena, 2014). Se informa, además, que esta situación es frecuente entre verbos que poseen uso transitivo junto a otro intransitivo, $\mathrm{o}$, como podrá verificarse entre los verbos que son objeto de estudio de este trabajo, los causativos de percepción, también pronominal cuyo sujeto es, en estos dos últimos casos, el objeto directo del uso transitivo; sirva de ejemplo: enfermar (se) (intr.) $=$ Causar enfermedad / enfermar (tr.) $=$ hacer que alguien contraiga enfermedad'.

Por último, ha de hacerse alusión a otro tipo de definición que presenta un carácter «marginal» por su menor frecuencia como por sus características formales aparecerá una construcción mediante un verbo subordinado, que fungirá como núcleo semántico, y otro auxiliar que expresará el contenido clasemático o aspectual.

Tal es el caso de las definiciones permisivas en las cuales se utiliza el verbo dejar, en el sentido de 'permitir', que irá acompañado por otro en infinitivo o en subjuntivo precedido de que: batir. tr. Dejar caer al suelo ${ }^{10}$. En estas definiciones, en palabras de Porto Dapena, se advierte el clasema de permisividad (si este definiens, de carácter permisivo, fuese precedida de la negación, podría convertirse en excluyente) (Porto Dapena, 2014).

\subsubsection{Contorno definicional}

Este término, según suele indicarse (Seco, 1979; Porto Dapena, 2014), bajo el nombre de entourage, había tenido sus inicios conceptuales

8 Citado por (Porto Dapena, 2014: 180).

9 Citado por (Porto Dapena, 2014: 181).

10 Íd., p.190. 
y teóricos en los trabajos de J. Rey-Debove (1971). En la lexicografía española se establece a partir de 1978 por M. Seco, aunque ya en el siglo XIx, los colombianos R. J. Cuervo y V. González Manrique lo habían adelantado o «intuido». No obstante, según informa M. Alvar Ezquerra (2012: 49-51) $)^{11}$, da noticias sobre un diccionario de 1846: Novísimo diccionario manual de la lengua castellana, redactado por una desconocida Sociedad de Literatos, en el que aún no de manera sistemática ya aparecían indicaciones referidas al contorno en verbos y adjetivos.

Ya son varios los diccionarios en los que se ha señalado el contorno: (ya «intuido por el DCR (1871)»); Diccionario Vox (1945); DUE (1966-1967); DS (1996); DEA (1999) ${ }^{12}$ y otros, como varios son también los símbolos que se han utilizado para resaltar los elementos contextuales.

Ahora bien, en relación con el contorno y su identificación con los elementos contextuales, Porto Dapena marca una división entre contorno y entorno, de donde restringe para el primero solo los elementos argumentales del definido:

[...] no todo elemento contextual de una definición lexicográfica constituye o forma parte del contorno de la misma pues este se reduce únicamente a lo que podemos llamar contexto argumental de la palabra definida, distinto de los contextos designativo o referencial, tropológico, geográfico o diatópico, cronológico o diacrónico, diastrático-diafásico, de usuarios, de especialidad y temático. Para todos estos otros contextos se propone el nombre de entorno (2014: 193).

En este sentido, pueden diferenciarse el contorno (o contexto argumental) y el resto de los contextos (o entorno), a partir de que solo el contorno puede formar parte del sintagma definicional (y entonces hablaremos de contorno integrado $(v .3 .2)$, pues «aun cuando pueda haber contornos no integrados (v.3.2), que no formen por consiguiente parte del

11 Citado en (Porto Dapena, 192, en nota al pie, N. ${ }^{\circ}$ ).

12 DCR: Diccionario de construcción y régimen; DUE: Diccionario de uso del español; DS: Diccionario Salamanca y DEA: Diccionario del español actual. 
https://doi.org/10.46744/bapl.201801.004

sintagma definicional, esto corresponderá obligatoriamente a cualquier contexto que no sea contorno» (Porto Dapena, 2014: 194).

El contorno definicional suele aparecer con mayor regularidad entre las definiciones de adjetivos y verbos. En estos últimos es normal que el contorno resalte los argumentos verbales, lo que tendrá especial importancia, pues pueden estos (o las variaciones que tengan lugar entre ellos y que, por tanto, repercutan en la estructura argumental) constituir la diferencia específica entre dos verbos de similar paradigma léxicosintáctico, o representar alguna condición exigida por el definido y evitar posibles confusiones al que intenta usar un determinado verbo (Porto Dapena, 2014: 195).

Según Porto Dapena, deberá indicarse «en grados diferentes» el contorno cuando el definiendum ofrece restricciones en relación con alguno o algunos de sus actantes o argumentos, si es un verbo (o si es un adjetivo, con el sustantivo a que se aplica); en otros casos, el contorno representa algún elemento pedido o fundamental del definiens sin el que este último no "puede funcionar»y, finalmente, puede suceder que el contorno indique funciones sintácticas diferentes (referidas al definiendum) a las que realiza con el definido (Porto Dapena, 2014: 205). En el DEA, por ejemplo, se usan regularmente los corchetes para indicar el contorno; pero cuando difiere la función sintáctica de definido y definidor, esta se especifica en abreviatura y entre paréntesis redondos (Porto Dapena, 2014: 208).

\subsubsection{Tipos de contorno}

El contorno podrá caracterizarse no solo por representar algún argumento del definiendum, sino también por poder formar sintácticamente parte del sintagma definicional (Porto Dapena, 2014).

No todos los contornos son obligatorios, sino que podrá suceder que un verbo pueda aparecer sin la indicación de alguno de sus argumentos porque estos puedan sobreentenderse fácilmente: Esa emisora informa siempre puntualmente (se omite qué informa y a quién se dirige, lo que en el contexto permite de alguna forma recuperarlos) (Porto Dapena, 
2014). En tal caso podrá hablarse de contorno opcional o que no puede materializarse en el discurso, que se diferencia del contorno fluctuante en que el primero no pasa a formar parte del significado del definiendum; mientras que el segundo podrá materializarse contextualmente, al lado del definido en algunos contextos y no aparecer en otros en los que llega a formar parte del enunciado parafrástico.

Entre los tipos de contorno que se distinguen (y sin pretensiones de hacer referencia a todos) se encuentra el integrado, que es aquel que forma parte del sintagma o enunciado definicional en el que desempeña determinadas funciones sintácticas que pueden coincidir o no con el o los argumentos del definido. Esta circunstancia da lugar, según Porto Dapena (2014), a una subclasificación, de modo que, si coincide la función sintáctica entre el definido y el definidor, se hablará de un contorno integrado homogéneo; por el contrario, si difieren ambas funciones, será un contorno integrado heterogéneo. De ambas posibilidades, aunque no siempre es posible (sobre todo en los verbos), el homogéneo sería «el ideal», pues no solo daría cuenta de las posibles restricciones a que se somete el argumento destacado, sino también ilustraría el comportamiento sintáctico con respecto a su definiendum (Porto Dapena, 2014).

Para el contorno integrado homogéneo, se establece, asimismo, otra división que alude al carácter fijo u obligatorio (cuando mantiene el estatus de contorno en todos los contextos o circunstancias en que se emplee el definido: "castigar. tr. Dañar o maltratar a alguien culpable de una falta o delito») frente a la posibilidad de ser fluctuante ${ }^{13}$ (funcionar unas veces como contorno o como parte del enunciado parafrástico: «comer. intr. Tomar alimento" que solo en el caso del uso transitivo del predicado funcionará alimento como verdadero contorno) (Porto Dapena, 2014) ${ }^{14}$.

13 Se volverá sobre este tipo de contorno, en tanto interesa en la relación entre predicados transitivo e intransitivo.

14 Además de la clasificación entre fijo o estable/fluctuante, tiene otra subdivisión. Como informa el profesor Dapena (2014: 214), es posible distinguir para el contorno fijo o estable otra subdivisión (obligatorio/opcional). 
https://doi.org/10.46744/bapl.201801.004

\subsubsection{El contorno verbal en el $D E A$}

Como se ha dicho — se pretende seguir la distinción ofrecida por Porto Dapena entre contorno y entorno-, el contorno hace referencia al contexto argumental. Luego, como ya se ha explicado, y por el carácter gramatical que se le concede (Bosque, 2008: 110), en los predicados verbales será el responsable de revelar (aunque no todas) las posibilidades combinatorias o sintagmáticas del definido. Luego, al menos en el $D E A$, que es el diccionario que se ha utilizado para este trabajo, el contorno referido a los verbos suele representar entre corchetes los argumentos («Muchas veces estas explicaciones de función se omiten por innecesarias, puesto que la misma fórmula definidora las da a entender con claridad» (Seco, Andrés, \& Ramos, 2005)), referidos a la función que a cada uno corresponde en los enunciados vivos (sujeto, complemento directo, complemento con la preposición en, etc.), función que se indica, cuando es preciso, entre paréntesis redondos.

\subsubsection{Contorno de predicados transitivos/intransitivos}

Como ya se adelantaba al inicio del trabajo (v. 1), en el $D E A$ los verbos suelen presentarse tras las marcas $t r$. o intr. Los contornos pertenecientes a los predicados transitivos resaltan, por lo general, en cada acepción y subacepción, el argumento referido al complemento directo del definido (con la especificación de la función sintáctica si esta difiere entre definido y definidor, lo que se identifica con un contorno integrado heterogéneo (v. $3.2)$ ), representados en unos casos solo por los indefinidos algo o alguien, y en otros, por estos indefinidos acompañados de un(os) modificador(es) que precisan o restringen al posible sustituto de los indefinidos; mientras que en otros casos se especifica un determinado referente.

Por su parte, en los intransitivos - ya sean predicados exclusivamente intransitivos, ya como intransitivos que presentan usos transitivos o transitivos dentro de los que se reporta un uso transitivo ${ }^{15}$ (por ejemplo: acontecer, acceder o abrigar, respectivamente) — se destaca sobre todo cuando no es predecible el argumento sujeto.

15 Esta subdivisión se ha hecho a partir de los verbos obtenidos en el vaciado realizado en la letra A. 


\subsubsection{Contorno fluctuante. Vínculos entre ambos tipos de predica- do: transitivo / intransitivo}

Entre los verbos - ya se ha dicho- es recurrente la presencia de este tipo de contorno. Se reconoce que, dentro de la «relativa frecuencia del contorno fluctuante», la mayor aparición se da con el complemento directo; sirva como ejemplo el citado por el profesor Dapena (2014: 219), «conducir. tr. Esp. Guiar un vehículo automóvil», en el que lo subrayado coincide, en esta acepción transitiva, efectivamente con el contorno (en este sentido, podría formularse un ejemplo como Pedro conduce un Mercedes de este año), mientras que en la intransitiva (por ejemplo: Pedro conduce muy bien) formaría parte, como se explicaba, del enunciado parafrástico. La posibilidad descrita para tal segmento: "poder funcionar alternativamente como contorno y como componente de la paráfrasis», y que se identifica con el contorno fluctuante, lo distingue del contorno opcional antes descrito (Porto Dapena, 2011: 116).

Con tal visto, podrá advertirse que tal tipo de contorno participa o puede mediar en los usos transitivos o intransitivos de un mismo verbo. Por consiguiente, podrá verificarse en «determinados contextos o circunstancias», en verbos transitivos que pueden perder su objeto directo o en intransitivos que se transitivizan y dan lugar a un complemento u objeto directo, que en algunos casos implica repetir la raíz del definiendum. Dado que tal fenómeno atañe al comportamiento de un argumento o actante (en el caso de la acepción transitiva) y, por tanto, a la estructura argumental repercutirá o podrá tener incidencia en la distribución que se haga de las acepciones en el diccionario. Se describe, entonces, este tipo de contorno como una de las «posibilidades transformativas que explican el paso de un verbo transitivo a intransitivo o viceversa $y$, por consiguiente, las relaciones semántico-sintácticas existentes entre ambas construcciones $[\ldots]$ » (Porto Dapena, 2011). 
https://doi.org/10.46744/bapl.201801.004

\section{Tratamiento lexicográfico de algunos verbos causativos de percepción en $D E A$}

\subsection{Cuestiones metodológicas}

\subsubsection{El Diccionario del español actual como fuente. Criterios para} su selección

El Diccionario del español actual (DEA), de Manuel Seco, Gabino Ramos y Olimpia Andrés, se erige sobre una base documental de textos españoles a partir de la segunda mitad del siglo xx, que acredita, en palabras de su autor, la redacción de la obra y que retoma lo que otrora hicieran los académicos del siglo xviII en el Diccionario de autoridades. El trabajo, que comienza en 1970, se basa en el léxico vivo y desatiende aquellas voces caídas en desuso, por tanto, es un producto lexicográfico de nueva planta. Es un diccionario general, sincrónico y descriptivo que aspira a dar noticias no solo del léxico que debe usarse, sino del que se usa. Al igual que otros diccionarios generales, es selectivo en cuanto a la inclusión de las unidades léxicas; solo recoge las palabras de España en los límites temporales expuestos.

En este diccionario, se privilegia la información gramatical. De ahí que tal interés guíe la estructuración del artículo lexicográfico que tiene en cuenta no solo lo relativo al significado, sino también las condiciones que la lengua impone para su utilización en los mensajes; es decir, la información relativa a su funcionamiento dentro de las estructuras gramaticales de la lengua. Así, se estructuran en grupos generales (I, II) las acepciones; además, «para simplificar las marcas, [...] en lugar de «verbo transitivo», «verbo intransitivo», nos limitamos a la indicación (tr. intr.)» (Seco, Andrés, \& Ramos, 2005: 19).

De igual forma, resulta útil no solo para la decodificación, sino también para la codificación que se establezcan grupos que se marcan con las letras mayúsculas en negrita (A y B), y que responden a "grandes alternativas sintácticas que determinan cambios de sentido». Asimismo, «[...] En muchos verbos, la capacidad de funcionar como transitivo o intransitivo (o bien, en algún caso, como copulativo o como intransitivo) también determina la formación de subgrupos» (Seco, Andrés, \& Ramos, 2005: 20). 
Finalmente, interesa el tratamiento que reciben las subacepciones «que siguen a la acepción y exponen uno o varios sentidos que, sin separarse marcadamente del presentado, se especializan en algún matiz, aspecto o dirección particular», en tanto se señalan por medio de una letra minúscula con cierre de paréntesis en negrita, a partir de la $b$ (Seco, Andrés, \& Ramos, 2005: 19). Un caso especial lo constituyen las referidas a la construcción pronominal «que las gramáticas llaman "voz media" $[\ldots]$ con la [...] se afirma que al sujeto le ocurre la acción del verbo, no, que la hace él ni [...] quién la ejecuta. Estas subacepciones van integradas en una acepción transitiva y con la marca pronominal (pr)» (Seco, Andrés, \& Ramos, 2005: 19).

\subsection{Verbos objeto de estudio}

Para el presente trabajo se han seleccionado, dentro de los verbos de percepción (según la clasificación del proyecto Alternancias de Diátesis y Esquemas Sintáctico-Semánticos del Español ${ }^{16}$ (Adesse), los causativos. Se han elegido estos con base en el trabajo «Aproximación empírica a la interacción empírica de verbos y esquemas construccionales, ejemplificada con los verbos de percepción", en el que se ubican dentro de la periferia de esta clase (García- Miguel, 2005). Así, llama la atención precisamente por no integrar la lista de los más frecuentes para esta clase entre los que se incluyen: «ver, mirar oír, encontrar, buscar, escuchar, mostrar, descubrir, contemplar y observar»). En este sentido, estos verbos son los que mejor caracterizan dicha clase semántica y «sirven de plantilla conceptual para otros verbos de percepción». De ahí que, aunque se hayan seleccionado los verbos que se ubican en la periferia, deben de compartir las características construccionales del resto de la clase, aunque con ello no se niega que pueda documentarse, asimismo, un amplio repertorio de variantes construccionales, incluso para un mismo verbo.

Ahora bien, si se hace una búsqueda en el sitio del proyecto Adesse, se podrá constatar que los verbos de percepción se ubican entre los más

16 El proyecto ADESSE reúne una base de datos con información sintáctico-semántica sobre los verbos del español. 
frecuentes con el esquema sintáctico SD ACTVA ${ }^{17}$, que explica precisamente que para estos verbos lo más frecuente es que se construyan en voz activa, con la participación de dos actantes o argumentos ${ }^{18} \mathrm{o}$, si se quiere, en una construcción transitiva.

Por otra parte, se incluyen en esta clase los verbos asociados a la percepción visual (ver, mirar), percepción auditiva (oír, escuchar), otros tipos de percepción sensorial (oler, saborear, tentar), así como verbos de percepción general (advertir, notar, percibir, detectar, percatarse, etc.). En la periferia semántica de la clase de percepción, se sitúan los verbos de búsqueda y hallazgo (buscar, encontrar, hallar, localizar) y los causativos de percepción (mostrar, enseñar, exhibir, descubrir, presentar, revelar, ocultar, camuflar, manifestar, exponer, exteriorizar, insinuar) (García-Miguel, 2005: 8).

\subsection{Análisis de los verbos seleccionados}

Los verbos mostrar, enseñar, exbibir, descubrir, revelar, ocultar, manifestar, exponer, exteriorizar, insinuar se describen, como se explicaba anteriormente, como causativos de percepción. Por tanto, se han buscado en el DEA para analizar el tratamiento lexicográfico que reciben. No se pretende un análisis exhaustivo, sino intentar hacer generalizaciones a partir de la descripción de determinados aspectos, tales como la posibilidad de admitir usos intransitivos junto con los transitivos (que son los descritos como más frecuentes), algunos de los tipos de contorno con estos verbos, así como la presencia de la voz media en subacepciones correspondientes a las transitivas de percepción visual.

\section{$\underline{\text { Subgrupos }}$}

En primer lugar, se analiza la posibilidad de distribuir las acepciones en subgrupos, pues se revelaría para estos verbos, además del uso primario descrito como parte de la clase semántica de percepción (el uso transitivo), también uno intransitivo. Esta información adquiere especial importancia si se repara en que este diccionario, como se dijo anterior-

17 Sujeto-objeto directo, en voz activa.

18 Para estos actantes se describen roles o papeles temáticos de un perceptor y un objeto percibidos. No obstante, no son estos objeto de estudio este trabajo. 
mente, se erige sobre una base documental que atiende al uso efectivo de la lengua.

En este sentido, se constata que estos verbos aparecen, en primera instancia, con la marca de verbo transitivo (tr.). Se corrobora, entonces, en este aspecto el que predomine con estos verbos el esquema sintáctico (SD ACTIVA) como lo descrito por Adesse.

En cuanto a la distribución de subgrupos en el artículo lexicográfico, lo que evidencia para estos verbos «las dos grandes alternativas construccionales que divide este diccionario» (tr. e intr.), puede decirse que presentarán dos subgrupos (A y B) los verbos: insinuar, exhibir, enseñar, manifestar, mostrar y ocultar, el resto de los verbos (descubrir, revelar, exponer, exteriorizar) tendrán, según este diccionario, solo un uso transitivo. En la mayoría de los verbos, el grupo B, que agrupa las acepciones intransitivas, coincide con un uso pronominal del verbo.

En cuanto a la distribución de las acepciones, aunque para revelar se marca un uso absoluto en la última (del que no se informa, por ejemplo, en la versión en línea del $D L E$ ), eso no impide que también se conciba esta acepción como transitiva. De presentarse alguna confusión para el lector, por haberse marcado este verbo como transitivo y por necesitar entonces dos argumentos (que no han dejado de existir), la ampliación sintagmática ilustra el posible uso, por lo que se confirma que no ha habido cambios en la estructura argumental, sino solo se ha omitido un argumento que se espera para este verbo (Porto Dapena, 2011: 129).

La expresión de la causatividad (o factitividad) en las definiciones a que dan lugar estos verbos en las acepciones referidas a la percepción visual

Por tratarse de verbos causativos, como los más numerosos entre los de acción, según la NGLE, pudiera esperarse que en la definición se perciba también una acción. Además, que se dé la posibilidad de que se comparta un argumento entre el defiendum y el definiens (que pueden o no diferir en la función sintáctica que asuman). 
https://doi.org/10.46744/bapl.201801.004

En este sentido, se tiene que se acude a la definición factitiva, por ejemplo, en «insinuar. 2., dejar ver o hacer notar [algo] de manera leve o imprecisa»; se utiliza el verbo hacer más un verbo en infinitivo, que sería el núcleo semántico del sintagma definicional y que comparte con el definidor el argumento referido al complemento directo: notar pasa a través de hacer a ser factitivo con respecto al definido. A esta definición factitiva, se coordina una definición permisiva, de modo que se le comunique al definido ambas posibilidades.

En el caso de enseñar. 2. Hacer saber o hacer ver [algo abstracto (cd) a alguien (ci)]. Aunque a veces se omite el $c i$. se presenta de igual forma, una definición factitiva, en la que interviene nuevamente el verbo hacer, esta vez con ver como núcleo semántico. Nótese en este caso que se destacan mediante el contorno los argumentos referidos a complemento directo e indirecto, con respecto al definiendum: especificar en este caso la función sintáctica disminuye la posible confusión, dado que el complemento indirecto aquí señalado constituye el sujeto del verbo no factitivo (ver) (igual sucede con saber, pero solo se atenderá —ya se decía— a la percepción visual).

Semejante definiens en parte lo tendrá mostrar en su acepción 2, hacer ver [algo que se ve o puede ser visto], con lo que se corrobora el que sea mostrar el causativo de ver. Por último, quisiera llamarse la atención sobre el caso de ocultar.1, A 1. Esconder (impedir que [alguien o algo (cd) esté visible]). Si se mira la especificación que se incluye entre paréntesis y que mejor logra explicar el sentido que se pretende en este caso), donde el verbo impedir, en función semejante a hacer, pero en forma negativa le comunica a estar visible el carácter factitivo. En este caso, el argumento compartido es para el no factitivo (estar visible), el sujeto, mientras que para el definido constituye el complemento directo.

En los demás verbos, en la acepción referida a la percepción visual no se utiliza el verbo hacer en el definiens (es recurrente la presencia de poner, no como núcleo semántico). No obstante, como ya se indicaba, no todo verbo causativo o factitivo tiene que ser necesariamente definido de forma factitiva (Porto Dapena, 2011). 


\section{Algunos tipos de contorno con estos verbos}

En general, el contorno con estos verbos muestra el argumento referido al complemento directo. Este se marca, como ya se indicaba, entre corchetes: en la mayoría de los casos con los indefinidos algo o alguien, referidos a cosa o persona, respectivamente.

En la mayoría de los verbos se presenta un contorno integrado, es decir, que forma parte del sintagma definicional, en unos casos homogéneo (que marca la misma función sintáctica para definido y definidor, en este caso el complemento directo), por ejemplo, en «manifestar. 2. Mostrar, o dejar ver [algo]». Frente a casos como el de ocultar (v. supra), en el que se trata de un contorno heterogéneo, por resaltarse un argumento que tiene diferente función sintáctica para definiedum que para definiens: complemento directo y sujeto, respectivamente.

La presencia de la voz media en las subacepciones correspondientes a las transitivas de percepción visual

Se incluye, con respecto a las acepciones transitivas de percepción, una subacepción que representa, según el prólogo, la voz media: «[...] con la voz media se afirma que al sujeto le ocurre la acción del verbo, no que la hace él ni por otra parte se indica quién la ejecuta. Esta subacepción va integrada en una acepción transitiva y con la marca pronominal (pr) (Seco, Andrés, \& Ramos, 2005: XIX)». En ocultar se advierte que el complemento directo, que el contorno delimita en 1, pudiera convertirse en sujeto en la acepción 1b. Constrúyase un ejemplo para 1. a partir del

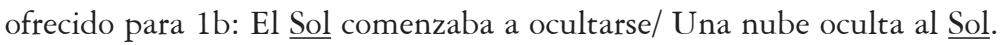
Ambas posibilidades se reúnen dentro de una subacepción que, según los autores del diccionario, «sigue a la acepción y expone un sentido que, sin separarse marcadamente del presentado, se especializa en algún matiz, aspecto o dirección particular [...]» (Seco, Andrés, \& Ramos, 2005: 19). En este caso, «ese matiz o aspecto en que se especializa» pudiera ser el cambio en la valencia, aunque con un argumento compartido que no deja de formar parte de la estructura argumental del predicado en cuestión, al menos de forma nocional. $Y$ es en este caso en el que podría hablarse de la «alternancia causativa» que caracteriza a los verbos causativos. Aparece, como ha podido verse, una variante transitiva y una inacusativa, en la 
https://doi.org/10.46744/bapl.201801.004

que el sujeto sintáctico es objeto nocional, en tanto se omite el sujeto nocional que se corresponde con la causa externa de la consecución del evento que denota el verbo. De ahí que resulte coherente ubicar a $1 \mathrm{~b}$ como subacepción de 1 . De ahí que pudiera ser la interpretación causativa de ocultar la que motiva a separar una primera acepción (1.) de la segunda transitiva (2.). Lo que confirmaría cómo el cambio en la estructura argumental (el aumento de un argumento) conlleva al cambio en el significado.

\section{Conclusiones}

Estudiar los artículos lexicográficos dedicados a algunos verbos de percepción, específicamente, mostrar, enseñar, exbibir, descubrir, revelar, ocultar, manifestar, exponer, exteriorizar e insinuar ha revelado que coinciden en que todos se marcan, en la primera de sus acepciones, de forma transitiva. Lo que está en correspondencia con lo descrito para la clase semántica de los verbos de percepción, cuyo esquema sintáctico más frecuente es SD ACTIVA. No obstante, se informa que suelen presentar una acepción que se marca como intransitiva pronominal.

En cuanto a la distribución de las acepciones con estos verbos, sobresale el que se ubiquen en las acepciones transitivas las de voz media, en tanto se mantiene el carácter de transitiva como en el caso de ocultar/ ocultarse, que muestra un caso de alternancia causativa.

Ahora bien, se observa que ver se usa en la mayoría de las acepciones, referidas a la percepción visual, como núcleo semántico en los sintagmas definicionales. Tal comportamiento interesa, en tanto se refiere precisamente a los verbos descritos como la "periferia de la percepción». Por otra parte, se observa que para la definición de estos verbos causativos de percepción no solo se utilizan definiciones factitivas (con el verbo hacer + infinitivo o hacer que + inf.), sino que también aparece, por ejemplo, la definición permisiva (dejar + infinitivo, que coincide con $v e r)$. No obstante, se cree que la definición factitiva logra mejor reflejar ese argumento que se incorpora en la noción de factitividad que asume el verbo no factitivo. 
https://doi.org/10.46744/bapl.201801.004

En relación con el contorno, se constató su eficacia (junto a la especificación de la función sintáctica) para la delimitación de los argumentos del definido, especialmente, en las acepciones factitivas de contorno heterogéneo; es decir, aquel en el que difieren las funciones sintácticas entre definido y definidor. Por consiguiente, este trabajo viene a confirmar la pertinencia de que el diccionario, en su propósito de brindar las herramientas para el conocimiento del idioma, atienda y exprese claramente los argumentos de los predicados.

Por otra parte, al extraer los verbos de las primeras 380 páginas de la letra $A$, con el fin de contrastar el número de verbos transitivos e intransitivos marcados como tal en el $D E A$, se obtuvo que la mayor representatividad pertenece a los marcados únicamente como transitivos, seguido de los que aceptan ambas posibilidades, de las cuales la transitiva marca el primer grupo de acepciones; mientras que de los otros dos grupos se encontraron menos casos. 
https://doi.org/10.46744/bapl.201801.004

\section{BIBLIOGRAFÍA}

BASSOLS DE CLIMENT, M. (1962). Sintaxis latina. Madrid: Consejo Superior de Investigaciones Científicas.

BOSQUE, I. (2008). «Combinatoria y significación. Algunas reflexiones». En I. Bosque, REDES. Diccionario combinatorio del español (págs. LXXIX-CLXIII). SM, Madrid.

. (s. f.). «Gramática y diccionario». En http://books. google.com.cu/books?id=hQGLOjZZfLYC\&pg $=$ PAS1\& Jpg $=$ PA518dq. 5 de julio de 2017.

BOSQUE, I., \& GUTIERREZ-REXACH, J. (2007). Gramática formal. Madrid.

CAMPOS, H. (1999). «Trannsitividad e Intransitividad». En I. BOSQUE \& V. DEMONTE, Gramática Descriptiva de la lengua española (págs. 1520-1574). Madrid: Espasa Calpe, S. A.

CANO, R. (1987). Estructuras sintácticas transitivas en el español actual. Madrid: Gredos, S. A.

COROMINAS, J. (1984). Diccionario crítico etimológico castellano e hispánico. Madrid: Gredos, S. A.

CUERVO, R. J. (1886). Diccionario de construcción y régimen de la lengua castellana (Vol. Primero). París: A. Rogers y F. Chernoviz, Libreros editores.

DAPENA, J.-Á. P. (s. f.). «Diccionario «Coruña» de la Lengua Española Actual». Disponible en https://www.udc.es/grupos/lexicografia/diccionario/3-3-El-caso-especial-de-los-verbos. htm. 4 de agosto de 2017. 
https://doi.org/10.46744/bapl.201801.004

DEMONTE, V. Predicados, argumentos y adjuntos en la gramática generativa. Disponible en https://www.uam.es/personal_pdi/filoyletras/vdemonte/termin.pdf. 3 de julio de 2017

. (s. f.). Transitividad, Intransitividad y papeles temáticos. Recuperado el junio de 2017.

ESCANDELL, V. M. (2011). Fundamentos de semántica composicional. Barcelona: Editorial Ariel.

GARCÍA- MIGUEL, J. M. (2005). Aproximación empirica a la interacción de verbos y esquemas construccionales, ejemplificada con los verbos de percepción. ELUA, 161-195.

IBÁÑEZ, S., \& MELIS, C. (2015). Ambivalencia transitiva y estructura argumental: resultados de un estudio de uso. Anuario de Letras. Linguistica y Filología, III(2), 153-197.

LEMA, M. M. (1981). «Los verbos causativos en español». Thesaurus, XXXVI(1), 14-22.

MELIS, C., \& ALFONSO, M. (2010). «La estructura argumental preferida de los verbos intransitivos y el concepto de marcación». Signos lingüisticos, 31-60.

MENDIKOETXEA, A. (1999). «Construcciones inacusativas y pasivas». En I. BOSQUE, \& V. DEMONTE, Gramática descriptiva de la lengua española (Vol. II, págs. 1571-1629). Madrid: Espasa Calpe, S. A.

PERIS, A. (2012). Nominalizaciones deverbales: denotación y estructural argumental. Barcelona, España.

PORTO DAPENA, J.-Á. (2002). Manual de técnica lexicográfica. Madrid: Arco/Libros S. A. 
https://doi.org/10.46744/bapl.201801.004

. (2011). «La definición lexicográfica de contorno fluctuante». Revista de lexicografía, XVII, 115-132.

. (2014). La definición lexicográfica. Madrid: Arco/Libros.

RAE-Asale. (2009). Nueva gramática de la lengua española. Madrid: Espasa libros, S. A.

ROCA PONS, J. (1968). Introducción a la gramática (Vol. II). La Habana: Instituto Cubano del Libro.

SECO, M. (1979). «El “contorno" en la definición lexicográfica». Homenaje a Don Samuel Gili y Gaya, in memoriam (pp. 183-191). Barcelona.

SECO, M., ANDRÉS, O., \& RAMOS, G. (2005). Diccionario del español actual. Madrid: Santillana, Ediciones Generales, S. L. 